\title{
Status of care for end stage kidney disease in countries and regions worldwide: international cross sectional survey
}

\author{
Aminu K Bello, ${ }^{1}$ Adeera Levin, ${ }^{2}$ Meaghan Lunney, ${ }^{3}$ Mohamed A Osman, ${ }^{4}$ Feng Ye, ${ }^{1}$ \\ Gloria E Ashuntantang, ${ }^{5}$ Ezequiel Bellorin-Font, ${ }^{6}$ Mohammed Benghanem Gharbi, ${ }^{7}$ \\ Sara N Davison, ${ }^{1}$ Mohammad Ghnaimat, ${ }^{8}$ Paul Harden, ${ }^{9}$ Htay Htay, ${ }^{10}$ Vivekanand Jha, ${ }^{11,12,13}$ \\ Kamyar Kalantar-Zadeh, ${ }^{14,15}$ Peter G Kerr, ${ }^{16,17}$ Scott Klarenbach, ${ }^{1}$ Csaba P Kovesdy, ${ }^{18,19}$ \\ Valerie A Luyckx, ${ }^{20,21}$ Brendon L Neuen, ${ }^{22}$ Donal O'Donoghue, ${ }^{23,24}$ Shahrzad Ossareh, ${ }^{25}$ \\ Jeffrey Perl, ${ }^{26,27}$ Harun Ur Rashid, ${ }^{28}$ Eric Rondeau, ${ }^{29,30}$ Emily See, ${ }^{31,32}$ Syed Saad, ${ }^{1}$ Laura Sola, ${ }^{33}$ \\ Irma Tchokhonelidze, ${ }^{34}$ Vladimir Tesar, ${ }^{35}$ Kriang Tungsanga, ${ }^{36,37}$ Rumeyza Turan Kazancioglu, ${ }^{38}$ \\ Angela Yee-Moon Wang, ${ }^{39}$ Natasha Wiebe, ${ }^{1}$ Chih-Wei Yang, ${ }^{40,41}$ Alexander Zemchenkov, ${ }^{42,43}$ \\ Ming-hui Zhao, ${ }^{44,45,46,47}$ Kitty J Jager, ${ }^{48}$ Fergus Caskey, ${ }^{49,50}$ Vlado Perkovic, ${ }^{51}$ Kailash K Jindal, ${ }^{1}$ \\ Ikechi G Okpechi, ${ }^{52,53}$ Marcello Tonelli, ${ }^{54,55}$ John Feehally, ${ }^{56}$ David C Harris, ${ }^{57}$ \\ David W Johnson ${ }^{58,59,60}$
}

For numbered affiliations see end of the article.

Correspondence to: A K Bello aminu1@ualberta.ca

(ORCID 0000-0002-6905-5937) Additional material is published online only. To view please visit the journal online.

Cite this as: $B M J$ 2019;367:15873 http://dx.doi.org/10.1136/bmi.l5873

Accepted: 23 September 2019

\section{ABSTRACT}

\section{OBJECTIVE}

To determine the global capacity (availability, accessibility, quality, and affordability) to deliver kidney replacement therapy (dialysis and transplantation) and conservative kidney management.

DESIGN

International cross sectional survey.

SETTING

International Society of Nephrology (ISN) survey of 182 countries from July to September 2018.

PARTICIPANTS

Key stakeholders identified by ISN's national and regional leaders.

MAIN OUTCOME MEASURES

Markers of national capacity to deliver core components of kidney replacement therapy and conservative kidney management.

\section{WHAT IS ALREADY KNOWN ON THIS TOPIC}

Over the past decade, understanding of the global epidemiology and economics of kidney disease has improved substantially

More data are available on the burden of acute kidney injury, chronic kidney disease, and end stage kidney disease, particularly in low and middle income countries

Despite their considerable impact on population health, acute kidney injury and chronic kidney disease are generally not included in international, regional, or national strategies for chronic disease control

\section{WHAT THIS STUDY ADDS}

This study provides a synopsis of the preparedness and capacity of health systems worldwide to meet the challenges of end stage kidney disease and associated health and economic impacts

It also gives a snapshot of the current capacity to deliver care for end stage kidney disease globally, by geographical region and income group, providing evidence to guide policy and practice, and enabling monitoring of progress There is substantial variability in the burden of end stage kidney disease and capacity for kidney replacement therapy and conservative kidney management, which have implications for policy

\section{RESULTS}

Responses were received from 160 (87.9\%) of 182 countries, comprising $97.8 \%$ (7338.5 million of 7501.3 million) of the world's population. A wide variation was found in capacity and structures for kidney replacement therapy and conservative kidney management-namely, funding mechanisms, health workforce, service delivery, and available technologies. Information on the prevalence of treated end stage kidney disease was available in 91 (42\%) of 218 countries worldwide. Estimates varied more than 800 -fold from 4 to 3392 per million population. Rwanda was the only low income country to report data on the prevalence of treated disease; 5 ( $110 \%)$ of 53 African countries reported these data. Of 159 countries, $102(64 \%)$ provided public funding for kidney replacement therapy. Sixty eight (43\%) of 159 countries charged no fees at the point of care delivery and 34 (21\%) made some charge. Haemodialysis was reported as available in $156(100 \%)$ of 156 countries, peritoneal dialysis in 119 (76\%) of 156 countries, and kidney transplantation in 114 (74\%) of 155 countries. Dialysis and kidney transplantation were available to more than $50 \%$ of patients in only $108(70 \%)$ and 45 (29\%) of 154 countries that offered these services, respectively. Conservative kidney management was available in 124 (81\%) of 154 countries. Worldwide, the median number of nephrologists was 9.96 per million population, which varied with income level.

CONCLUSIONS

These comprehensive data show the capacity of countries (including low income countries) to provide optimal care for patients with end stage kidney disease. They demonstrate substantial variability in the burden of such disease and capacity for kidney replacement therapy and conservative kidney management, which have implications for policy.

\section{Introduction}

When chronic kidney disease progresses to the end stage, kidney replacement therapy (dialysis or kidney transplantation) or conservative kidney management (planned, holistic, patient centred care for those with 
stage 5 chronic kidney disease) is required..$^{1-4}$ Extensive study has been made of the costs and consequences of kidney disease-from acute kidney injury to chronic kidney disease to end stage kidney disease. ${ }^{5-7}$ Global variations in the burden of kidney disease, related care practices, and their determinants have been well documented..$^{\text {7-15 }}$ Consistent and comparable data describing the global capacity to deliver kidney replacement therapy and conservative kidney management have not been reported previously.

The International Society of Nephrology (ISN) led the Global Kidney Health Atlas project to define the global capacity for kidney care through a multinational, cross sectional survey. ${ }^{16}$ The first iteration of the project in 2017 explored global international and intranational variability in the capacity for kidney care delivery, as defined by the World Health Organization. The 2017 Atlas showed significant inter-regional and intraregional variability in global kidney care, with appreciable gaps in universal health coverage. ${ }^{16}$ One of the limitations then shown was the lack of detail on important elements of care, such as accessibility, affordability, and quality of end stage kidney disease care. $^{17}$

This second Global Kidney Health Atlas survey aimed at extending the findings of the first and defining the global capacity to deliver care for end stage kidney disease. Specifically, it includes metrics of availability, accessibility, quality, and affordability of services. The survey assesses the ability of nations to meet the needs of populations for integrated care, including access to kidney replacement therapy and conservative kidney management. It complements existing data on the global burden of end stage kidney disease and is a useful tool for policy makers, allowing assessment of, and comparison with, countries and regions which are dealing with the problem, especially in low and middle income countries.

\section{Methods}

This iteration of the Global Kidney Health Atlas is the product of collaborative efforts with regional and national project leaders. Detailed methods are published elsewhere. ${ }^{1618}$ In brief, two approaches were used. Firstly, a systematic review of literature and other data sources was carried out to calculate estimates of the burden of kidney replacement therapy. This burden was defined as the incidence and prevalence of end stage kidney disease (overall), and the treatments used (that is, haemodialysis, peritoneal dialysis, and kidney transplantation). A previously published framework was adapted and expanded. ${ }^{19}$ Data were extracted from key reports, including annual reports of end stage kidney disease, kidney registries, and databases such as the global observatory on donation and transplantation. ${ }^{20}$ In places where no data exist in major kidney registries (eg, United States Renal Data System, European Renal Association-European Dialysis and Transplant Association, and Australian and New Zealand Dialysis and Transplant Register), additional published and grey literature was searched.
Secondly, a key opinion leader survey was carried out. Three leaders from each country (a nephrology society leader, a leader of a patient representative organisation, and a policy maker) submitted details on national kidney care practices, with a specific focus on kidney replacement therapy and conservative kidney management. We sought assistance from international contacts, collaborators, ISN leaders, and regional board members to facilitate both approaches during the development of the Global Kidney Health Atlas. Project leaders, regionally and nationally, ensured that local nephrology association leaders, patient representatives, policy makers, and other opinion leaders were included. They also organised and followed up the responses from all countries and liaised between the steering committee, ISN, and regional stakeholders; helped to gain access to additional data sources and contacts; identified or served as opinion leaders on the project for each specific region; and vetted and reviewed regional data, or identified others to do so.

\section{Survey administration}

The survey was sent electronically to people in 182 countries with ISN affiliate societies. It was coordinated through the society's 10 regional boards-namely, Africa, central and eastern Europe, Latin America, the Middle East, North America, north and east Asia, Oceania and South East Asia, newly independent states and Russia, south Asia, and western Europe (eFig 1).

The project was approved by the University of Alberta research ethics committee (protocol number: PRO00063121). All participants provided informed consent. A non-probability, purposive sampling approach was used to identify potential survey respondents. Specifically, national and regional nephrology leaders identified key stakeholders through the ISN. These included representatives of national nephrology societies, policy makers (comprising those directly responsible for the organisation of kidney care and those with more general responsibilities), patient organisations, foundations, and other advocacy groups. Key stakeholders were sent an invitation to participate. This included a link to the survey's online portal (an electronic questionnaire via REDCap Cloud, https://www.redcapcloud.com). The survey was conducted from July to September 2018. During this period, regional and national leaders of the ISN carried out intensive follow-up by email and telephone to ensure complete and timely responses.

\section{Development and validation of the survey instrument}

The design of the survey questionnaire has been described previously. ${ }^{16} 18$ The questionnaire was further developed through a series of reviews with the executive committee of the ISN and regional leadership. It was peer reviewed for content validity and comprehensiveness before being tested with the 10 regional boards of the ISN to identify any logistical 
and feasibility problems (eg, need for translation). The format and content were finalised based on feedback, and the original English language survey questionnaire (eAppendix 1) was translated into French and Spanish.

The questionnaire was designed in five modules that assessed the national and regional profiles for capacity and response to end stage kidney disease. These corresponded to each of the six building blocks of health systems towards universal health coverage. ${ }^{18} 21$ The questionnaire was accompanied by information about the Global Kidney Health Atlas, detailed instructions for completion, and a glossary of the key terms used in the survey.

\section{Data handling and reporting}

Responses to the French and Spanish surveys were first converted to English by certified translators. Data from all individual questionnaires were subsequently extracted to Microsoft Excel, cleaned, merged, and then combined into a single file to create the global database for analysis using Stata 15 software (Stata Corporation, 2017).

Responses between respondents from the same country were concordant in $112(70 \%)$ of 160 cases. Regional leaders of the ISN were asked to ensure that collated data were consistent with their understanding and were of high quality. Each regional board clarified any ambiguities or inconsistencies. Any major inconsistencies remaining after the reviews were dealt with systematically during follow-up with the survey stakeholders. Findings were further validated nationally and regionally by triangulating with published literature and grey sources of information (eg, government reports and other sources provided by the survey respondents).

\section{Data analysis and definition of variables}

We used Stata 15 software (Stata, College Station, TX) to analyse the data. ${ }^{22-24}$ Using country as the unit of analysis, we synthesised data from multiple respondents into a single response for each country by contacting regional board representatives to deal with data discrepancies. We used a descriptive statistical approach to summarise responses to key questionnaire domains, and reported counts and percentages. We then stratified the results by ISN region and by World Bank income group.

We defined the components of kidney replacement therapy (dialysis and transplantation) and elements of care delivery based on established frameworks. ${ }^{25}$ Conservative kidney management was defined and analysed based on the Kidney Disease Improving Global Outcomes' (KDIGO) conventions and metrics. ${ }^{4}$ Conservative kidney management was defined as planned, holistic, patient centred care for patients with chronic kidney disease stage 5. It includes interventions to delay progression of the disease and minimise complications but focuses predominantly on management of symptoms and psychological, social, cultural, and spiritual support. It does not include dialysis.
We defined the key standards of availability, accessibility, quality, and affordability based on standard metrics. ${ }^{26}$ Availability was classified as "generally available" (in $\geq 50 \%$ centres, hospitals, or clinics) or "generally not available" (in $<50 \%$ ). We defined accessibility as the proportion of patients able to access a given service (eg, dialysis). Quality was defined as the proportion of centres that routinely measured a given indicator (eg, blood pressure) to assess the quality of the service provided. We defined affordability as the proportion of the treatment cost paid for directly by the patient. Patient reported outcome measures were defined as health outcomes reported directly by the patient without interpretation of their response by others. ${ }^{27}$ To increase the clarity in the survey, we provided examples, including fatigue, quality of life, satisfaction, and pain.

We examined the results with an emphasis on identifying key gaps in, and challenges to, the delivery of kidney replacement therapy and conservative kidney management according to the Guidelines for Accurate and Transparent Health Estimates Reporting (GATHER) statement. ${ }^{24}$ We followed the Checklist for Reporting Results of Internet E-Surveys (CHERRIES) ${ }^{28}$ to describe survey development and administration, analysis, and reporting (eAppendix 2). Respondents were asked to report the number of centres in their countries providing kidney replacement services (haemodialysis, peritoneal dialysis, and kidney transplantation). The concentration overall, by World Bank income group and country, was then computed by dividing the total number of centres by the overall population in millions. Population estimates were obtained from the Central Intelligence Agency World Factbook midyear 2018. A similar approach was used to measure the density of nephrologists and nephrology trainees. This is a widely used approach to report numbers and distribution of health services and resources relative to the population size. ${ }^{21}$

\section{Patient and public involvement}

Patient care organisations (kidney foundations, patients' associations) were involved in the development of the survey instrument. The following organisations were involved in the survey, and their representatives were also selected to respond to the survey: International Federation of Kidney Foundations, European Kidney Patients' Federation (an umbrella organisation for national kidney patients' associations in Europe), Kidney Foundation of Canada, US National Kidney Foundation, and Kidney Health Australia. The knowledge dissemination plan will involve these consumer organisations. The target end users of this research are these consumer organisations, policy makers, healthcare providers responsible for delivering kidney care, non-profit or advocacy organisations, and the public. The design of the project was led by nephrologists and the ISN. Individual patient data were not used in this study; it was rather a survey of healthcare structure and delivery and was not based on patient data. Further, there was considerable 
involvement of policy makers (nephrology society leaders and kidney care administrators). We plan to disseminate this work widely through the media, government groups (ministries of health), and to other international stakeholder organisations such as the United Nations, WHO, and the World Bank through a variety of approaches (eAppendix 3). The report is publicly available on the ISN's website (https:// www2.theisn.org/GKHA) and has received coverage from news media (https://www.theisn.org/images/ GKHA_media_coverage.pdf). Additionally, the ISN's regional board members receive the report directly so that they can disseminate it to their country focal leads and ministers of health. Each country is given a country score card, which displays their country level data for all key indicators, allowing leaders to identify where their country stands relative to the ISN's region and income group. A number of substudy analyses will be published in peer reviewed journals. An interactive data repository will be created to make the Global Kidney Health Atlas data and score cards publicly available across countries.

\section{Results}

\section{Response rate}

Responses were received from 160 (87.9\%) of 182 countries, comprising $97.8 \%$ (7338.5 million of 7501.3 million) of the world's population (table 1, eFig 2). The individual response rate was $68.9 \%$ (that is, $317 / 460$ individuals) and the median number of respondents from each country was 3 (interquartile range 2-4; eTable 1). Results showed statistically significant variability among countries in the distribution of capacity for kidney replacement therapy and conservative kidney management. Important gaps were seen in services (including drug treatment, funding, and registries), advocacy structures, and workforce (eAppendix 4).

\section{Country readiness, capacity, and response to end stage kidney disease}

Disease burden: regional and country level distribution

Information on the prevalence of treated end stage kidney disease was available in 91 (42\%) of 218 countries (fig 1), of which most were high or upper middle income countries. Only one low income country (Rwanda) and five (9\%) of 53 African countries provided data on the prevalence of treated end stage kidney disease (fig 1). The median prevalence of kidney replacement therapy globally was 759 per million population (pmp), varying from $4 \mathrm{pmp}$ in Rwanda to 3392 pmp in Taiwan (fig 1). Similarly, data on the incidence of treated end stage kidney disease were available in 79 (36\%) of 218 countries (fig 2). No low income country and only four $(<10 \%)$ of 53 African countries reported incidence data (fig 2 ). The median rate of treated end stage kidney disease worldwide was $144 \mathrm{pmp}$, ranging from $20 \mathrm{pmp}$ in Paraguay to 493 pmp in Taiwan (fig 2). Data on individual kidney replacement therapy components-chronic dialysis (haemodialysis and peritoneal dialysis) and kidney transplantation (deceased and living donors)-are shown in eFigures 3-12. Information on pre-emptive kidney transplantation was available in only 20 (9\%) of 218 countries. The median rate of pre-emptive kidney transplantation operations worldwide was 5.2 pmp, ranging from $0.3 \mathrm{pmp}$ in Bosnia and Herzegovina to 12.4 pmp in Norway (fig 3).

Capacity for provision of kidney replacement therapy The capacity to deliver chronic dialysis and kidney transplantation services varied around the globe (eFigs 3-12). Among the 156 countries with chronic haemodialysis services, the median number of haemodialysis centres was $4.5 \mathrm{pmp}$ (eFig 13). Among the 119 countries with chronic peritoneal dialysis services, 117 had peritoneal dialysis centres; the global median was 1.3 centres pmp (eFig 14). Among the 114 countries with kidney transplantation services, 113 had transplantation centres; the global median was 0.4 centres pmp (eFig 15). Among the countries with kidney transplantation services, the sources of donated kidneys varied. Eighty two (72\%) of 114 kidneys were obtained from both deceased and living donors, and only 32 (28\%) were obtained from living donors. Of the 113 countries offering kidney transplantation, 70 (62\%) had national waiting lists, 22 (19\%) had only regional waiting lists, and 21 (19\%) had no waiting list (eTable 2).

The availability of kidney replacement does not yield much insight into access to treatment. Therefore, we also assessed the proportion of countries in which more than $50 \%$ of medically suitable patients reportedly received kidney replacement therapy (eTable 3). At least half of such patients could access dialysis in 108 (70\%) of 154 countries with the service available. Treatment with peritoneal dialysis first could be started in at least half of suitable patients in five (3\%) of 154 responding countries, but in fewer than a quarter of patients in $96(62 \%)$ countries. Access to kidney transplantation was possible for most patients $(\geq 50 \%)$ in $45(29 \%)$ of 154 responding countries, but to only a quarter of patients in $56(36 \%)$ countries (eTable 3).

Access to kidney replacement therapy was associated with country income-for example, only one low income country could offer it to more than $50 \%$ of medically suitable patients. Similarly, neither peritoneal dialysis as the initial dialysis modality nor kidney transplantation was available for any patients in $18(82 \%)$ and 17 (77\%) of 22 low income countries, respectively. Haemodialysis at home was available for only 20 (13\%) of 154 countries-all high income countries. Most of these were in western Europe $(n=13)$, and the rest were in Latin America $(n=1)$, the Middle East $(n=1)$, North America $(n=2)$, and Oceania and South East Asia $(n=3)$.

\section{Capacity for conservative kidney management provision}

Conservative kidney management, as defined by KDIGO, was available in 124 (81\%) of 154 countries. 


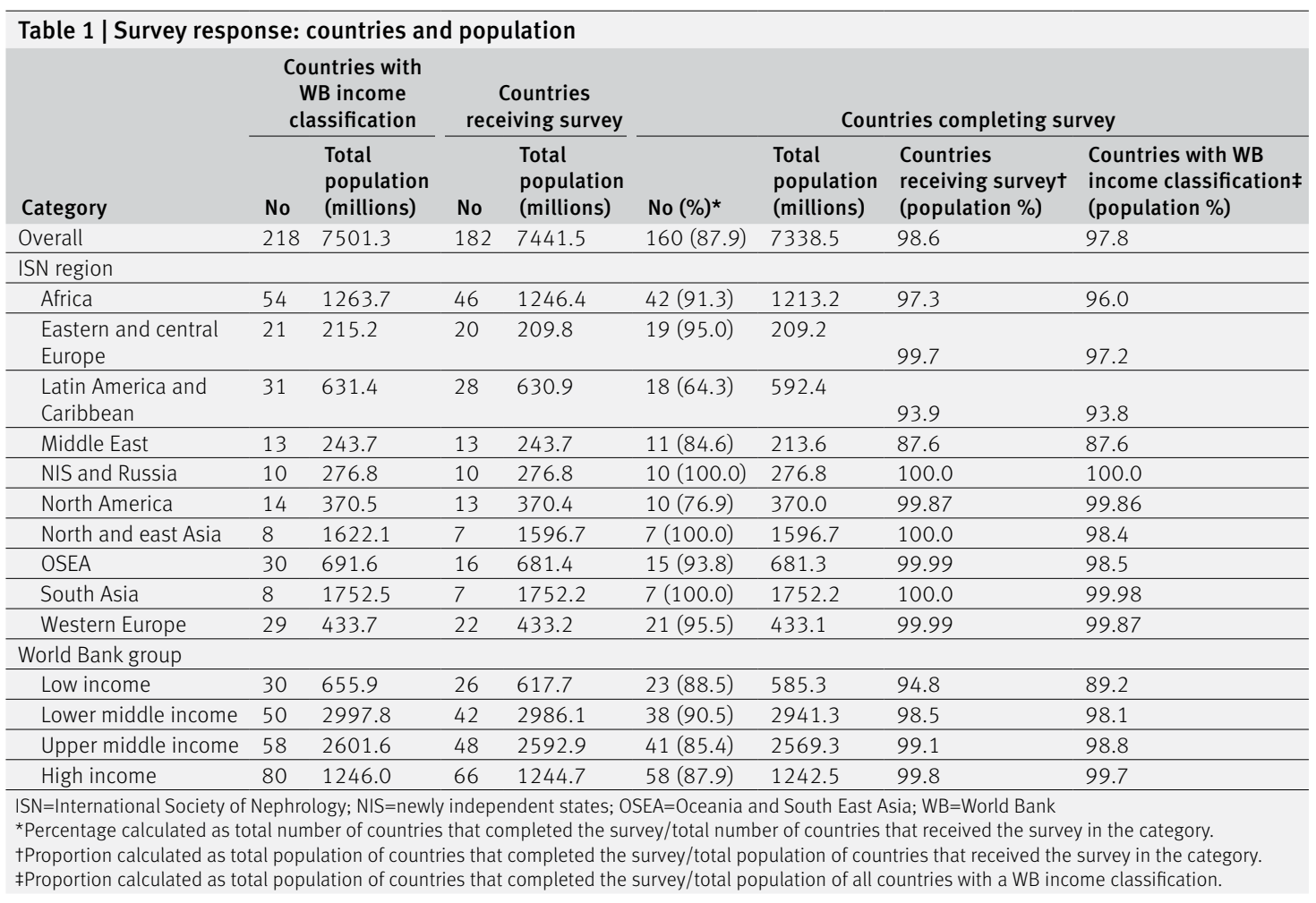

In 66 (43\%), choice was restricted (limited by capacity to provide kidney replacement therapy) owing to lack of resources. In 77 (50\%) countries, medically advised kidney management (conservative care based on a patient's choice or medical decision that is not limited by capacity to provide kidney replacement therapy) was available.

All countries in north, east, and south Asia, and most countries in eastern and central Europe (95\%, 18/19), Oceania and South East Asia (93\%, 14/15), western Europe $(90 \%, 18 / 20)$, the Middle East $(82 \%, 9 / 11)$, and Africa $(80 \%, 33 / 41)$, offered conservative kidney management (eTable 4). In contrast, this was offered by fewer than half of the countries in Latin America $(44 \%, 8 / 18)$, and just over half of the countries in newly independent states and Russia $(57 \%, 4 / 7)$ and North America (67\%, 6/9; eTable 4). The availability of conservative kidney management did not appear to be associated with income level: it was provided by $84 \%(47 / 56)$ of high, $80 \%$ (33/41) of upper middle, $74 \%(26 / 35)$ of lower middle, and $82 \%(18 / 22)$ of low income countries (eTable 4). Medically advised conservative kidney management, however, increased with country income (eTable 4). Moreover, 57 (37\%) of 154 countries with conservative kidney management adopted a multidisciplinary team approach to care

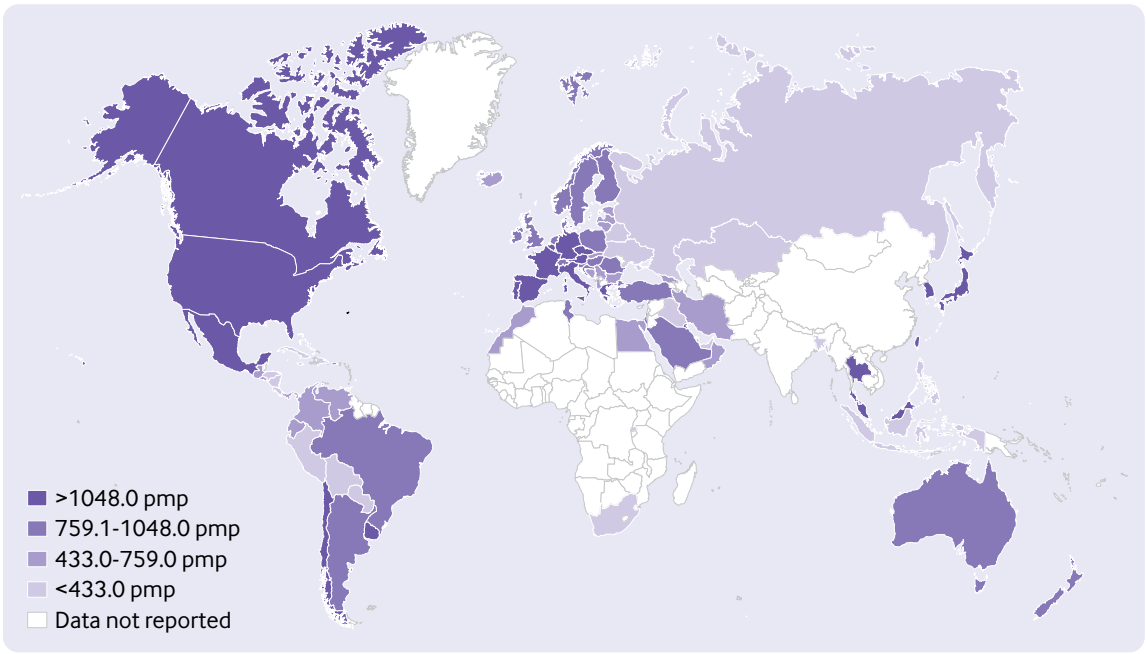

Fig 1 | Global prevalence of treated end stage kidney disease, based on individual country data. pmp=per million population 


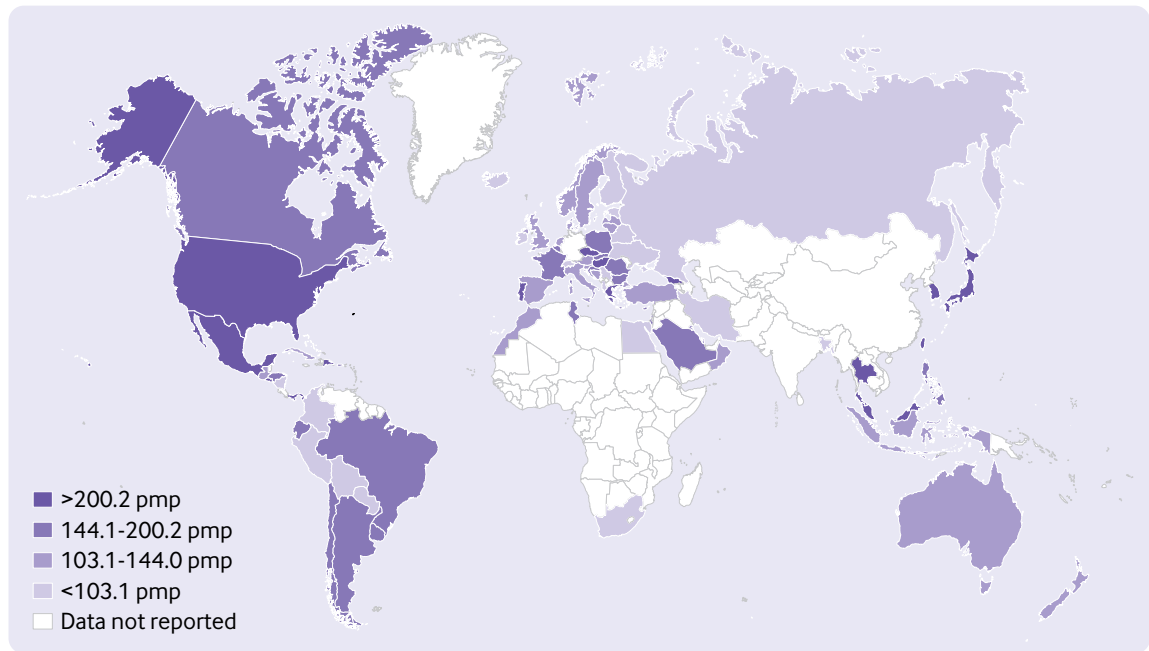

Fig 2 | Global incidence of treated end stage kidney disease, based on individual country data. pmp=per million population

and 40 (26\%) used shared decision making tools (eg, practice guidelines for providers and patient decision aids). Systematic active recognition and management of symptoms associated with advanced kidney failure were generally available in 80 (52\%) of 154 countries. Psychological, cultural, and spiritual support were provided to people receiving conservative kidney management in only 45 (29\%) countries (eTable 4).

\section{Health system financing for kidney replacement} therapy

Overall, 102 (64\%) of 159 countries provided public funding for kidney replacement therapy. No fees were charged at point of delivery by $68(43 \%)$ countries, and some fees were charged by 34 (21\%; table 2). Kidney replacement therapy was funded through a mix of public and private systems in 34 (21\%) of 159 countries and through multiple systems (governments, non-governmental organisations, and communities) in $10(6 \%)$ countries (table 2). Public funding (with or without fees at the point of delivery) was less common in low income countries (table 2). Coverage for surgical services for kidney replacement therapy, including fistula, graft, and catheter procedures for haemodialysis, catheter insertion for peritoneal dialysis, and kidney transplantation, varied worldwide. For instance, over half of all countries provided public funding for surgery to create vascular access for haemodialysis: 92 (58\%) of 159 covered central venous catheter insertion, and 86 (54\%) covered fistula or graft creation (eTable 5).

Patient copayments (that is, the proportion of the treatment cost, including drugs, paid for directly out of pocket) for kidney replacement therapy varied around the globe (eTable 6). Among the 154 countries with haemodialysis available, $41(27 \%)$ had no patient copayment, whereas in $23(15 \%)$ countries, patients paid more than $75 \%$ of the haemodialysis cost. In $35(23 \%)$ responding countries, patients

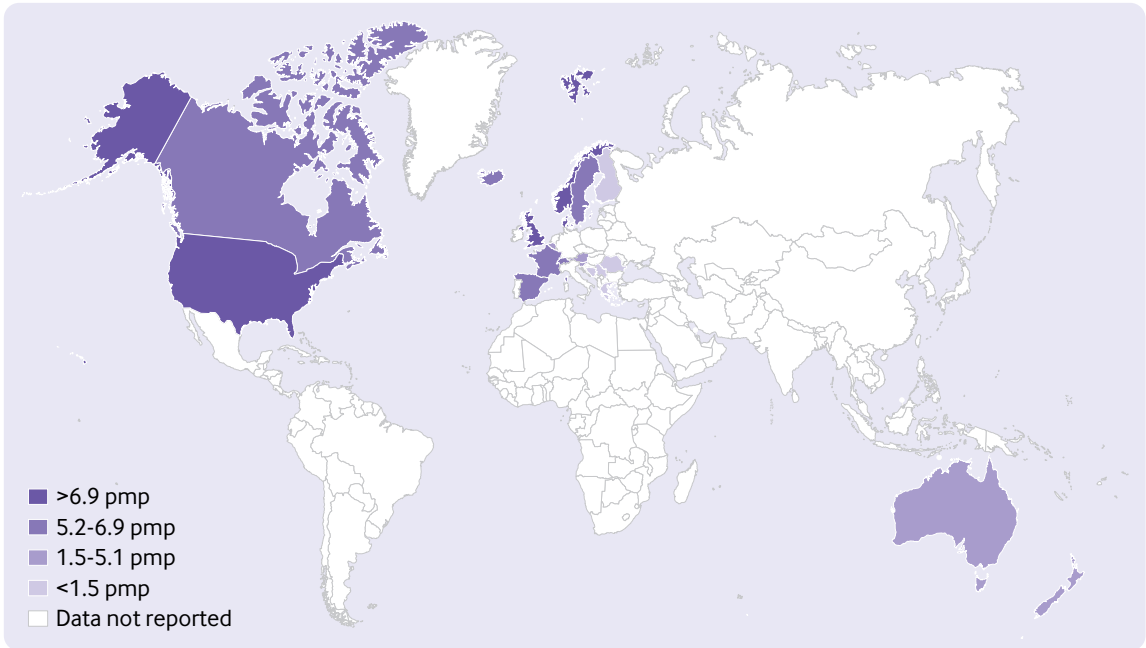

Fig 3 | Global incidence of pre-emptive kidney transplantation (that is, receiving a kidney transplant before the need to start dialysis), based on individual country data. $\mathrm{pmp}=$ per million population 


\begin{tabular}{|c|c|c|c|c|c|c|c|c|c|}
\hline \multirow[b]{2}{*}{ Category } & \multirow[b]{2}{*}{$\begin{array}{l}\text { No of } \\
\text { responding } \\
\text { countries }\end{array}$} & \multicolumn{2}{|c|}{ Public } & \multirow[b]{2}{*}{$\begin{array}{l}\text { Mix of } \\
\text { public and } \\
\text { private }\end{array}$} & \multicolumn{2}{|c|}{ Private } & \multirow[b]{2}{*}{$\begin{array}{l}\text { Multiple } \\
\text { systems* }\end{array}$} & \multirow[b]{2}{*}{ N/At } & \multirow[b]{2}{*}{ Otherf } \\
\hline & & $\begin{array}{l}\text { Free at point } \\
\text { of delivery }\end{array}$ & $\begin{array}{l}\text { Some fees } \\
\text { at point of } \\
\text { delivery }\end{array}$ & & $\begin{array}{l}\text { Out of } \\
\text { pocket }\end{array}$ & $\begin{array}{l}\text { Health } \\
\text { insurance }\end{array}$ & & & \\
\hline Overall & 159 & $68(43)$ & $34(21)$ & $34(21)$ & $7(4)$ & $1(1)$ & $10(6)$ & $1(1)$ & $4(3)$ \\
\hline \multicolumn{10}{|l|}{ ISN region } \\
\hline $\begin{array}{l}\text { Latin America } \\
\text { and Caribbean }\end{array}$ & 18 & $4(22)$ & $3(17)$ & $9(50)$ & $1(6)$ & $0(0)$ & $1(6)$ & $0(0)$ & $0(0)$ \\
\hline Middle East & 11 & $10(91)$ & $1(9)$ & $0(0)$ & $0(0)$ & $0(0)$ & $0(0)$ & $0(0)$ & $0(0)$ \\
\hline NIS and Russia & 9 & $6(67)$ & $2(22)$ & $0(0)$ & $0(0)$ & $0(0)$ & $0(0)$ & $0(0)$ & $1(11)$ \\
\hline South Asia & 7 & $1(14)$ & $1(14)$ & $1(14)$ & $1(14)$ & $0(0)$ & $3(43)$ & $0(0)$ & $0(0)$ \\
\hline Western Europe & 21 & $14(67)$ & $5(24)$ & $0(0)$ & $0(0)$ & $1(5)$ & $0(0)$ & $0(0)$ & $1(5)$ \\
\hline \multicolumn{10}{|l|}{ World Bank group } \\
\hline Low income & 23 & $5(22)$ & $6(26)$ & $5(22)$ & $4(17)$ & $0(0)$ & $1(4)$ & $1(4)$ & $1(4)$ \\
\hline Lower middle income & 37 & $11(30)$ & $10(27)$ & $6(16)$ & $2(5)$ & $0(0)$ & 7 (19) & $0(0)$ & $1(3)$ \\
\hline Upper middle income & 41 & $18(44)$ & $7(17)$ & $15(37)$ & $0(0)$ & $0(0)$ & $1(2)$ & $0(0)$ & $0(0)$ \\
\hline High income & 58 & $34(59)$ & $11(19)$ & $8(14)$ & $1(2)$ & $1(2)$ & $1(2)$ & $0(0)$ & $2(3)$ \\
\hline $\begin{array}{l}\text { ISN=International Society } \\
\text { *Programmes provided b } \\
\text { tKidney replacement ther } \\
\text { ‡Other funding mechanis }\end{array}$ & $\begin{array}{l}\text { of Nephrology; } \\
\text { governments, } n \\
\text { apy not available }\end{array}$ & $\begin{array}{l}\text { S=newly indepen } \\
\text { n-governmental o } \\
\text { the survey. }\end{array}$ & $\begin{array}{l}\text { dent states; OS } \\
\text { rganisations, a }\end{array}$ & $\begin{array}{l}\text { =0ceania and } \\
\text { communities. }\end{array}$ & South Eas & & & & \\
\hline
\end{tabular}

had no copayment for peritoneal dialysis, but in 16 $(10 \%)$ countries, patients paid more than $75 \%$ of the cost. In 113 countries where kidney transplantation services were available, 35 (31\%) had no patient copayment, but 15 (13\%) had patients paying more than $75 \%$ of kidney transplantation costs (eTable 6). Patient copayment for dialysis was the highest in low income countries, where more than $75 \%$ of the cost for haemodialysis and peritoneal dialysis was out of pocket in eight (36\%) and four (18\%) of 22 countries, respectively. Copayment for kidney transplantation was the highest in lower middle income countries, with patients covering more than $75 \%$ of the cost in seven (29\%) of 24 countries (eTable 6).

\section{Funding for drugs used in end stage kidney disease} care

Among the 153 countries that offered dialysis, 94 (61\%) provided government funding for patients' drugs; 62 countries charged patients no fees and 32 charged some fees at the point of delivery (table 3 ). In contrast, $15(10 \%)$ of 153 countries funded drugs for patients undergoing dialysis exclusively through private sources (table 3). Among the 113 countries that offered kidney transplantation, 84 (74\%) covered drug treatment costs through government funding; 64 countries charged patients no fees and 20 charged some fees at the point of delivery (table 4). In contrast, six (5\%) of 113 funded drugs for transplant patients exclusively through private sources (table 4).

\section{Availability of services for end stage kidney disease care}

Availability of services for end stage kidney disease care (that is, diagnostic tests and treatment for blood pressure, anaemia, renal bone disease, electrolytes, and acid base disorders) varied globally. Availability was limited greatly among low income countries (eTables 7-9). Most countries had the capacity to measure serum haemoglobin, provide oral iron supplementation, and monitor iron variables (eTable 7). Fewer countries had the capacity to administer non-calcium-based phosphate binders (47\%, 73/155) and cinacalcet $(37 \%, 58 / 155)$ (eTable 8$)$. The capacity to manage electrolyte disorders and chronic metabolic acidosis was high in most countries (eTable 9).

\section{Workforce for delivery of end stage kidney disease care}

Respondents were asked to estimate the number of nephrologists and nephrology trainees, as defined by regulatory authorities, and provide details of their role. Additionally, they were asked whether there was a shortage (yes/no) of the workforce required for delivery of end stage kidney disease care. Overall, nephrologists were primarily responsible for care for end stage kidney disease in 144 (92\%) of 157 countries. Care was also provided by primary care physicians jointly with nephrologists in 34 (22\%) of 157 countries. Other providers were primarily responsible for end stage kidney disease care in three (2\%) of 157 countries. Worldwide, the median number of nephrologists was $9.96 \mathrm{pmp}$ (eFig 16). The number of nephrologists by country increased with income level, with low income countries having the lowest prevalence $(0.4 \mathrm{pmp})$, followed by lower middle (5.0 pmp), upper middle (13.5 pmp), and high (26.5 pmp) income countries (eFig 16). The median number of nephrology trainees was $1.4 \mathrm{pmp}$ (eFig 17), with considerable variation across countries (eFig 17). All countries reported shortages of providers essential for end stage kidney disease care (eFig 


\begin{tabular}{|c|c|c|c|c|c|c|c|c|}
\hline \multirow[b]{2}{*}{ Category } & \multirow[b]{2}{*}{$\begin{array}{l}\text { No of } \\
\text { responding } \\
\text { countries }\end{array}$} & \multicolumn{7}{|c|}{ All patients receiving dialysis } \\
\hline & & $\begin{array}{l}\text { Free at point } \\
\text { of delivery }\end{array}$ & $\begin{array}{l}\text { Some fees } \\
\text { at point of } \\
\text { delivery }\end{array}$ & $\begin{array}{l}\text { Mix of public } \\
\text { and private } \\
\text { funding }\end{array}$ & $\begin{array}{l}\text { Out of } \\
\text { pocket }\end{array}$ & $\begin{array}{l}\text { Heath } \\
\text { insurance }\end{array}$ & $\begin{array}{l}\text { Multiple } \\
\text { systems* }\end{array}$ & Othert \\
\hline \multicolumn{9}{|l|}{ ISN region } \\
\hline Africa & 40 & $9(23)$ & $6(15)$ & $12(30)$ & $10(25)$ & $1(3)$ & $2(5)$ & $0(0)$ \\
\hline Eastern and central Europe & 19 & $18(95)$ & $1(5)$ & $0(0)$ & $0(0)$ & $0(0)$ & $0(0)$ & $0(0)$ \\
\hline Latin America and Caribbean & 18 & $5(28)$ & $3(17)$ & $8(44)$ & $1(6)$ & $0(0)$ & $1(6)$ & $0(0)$ \\
\hline Middle East & 11 & $8(73)$ & $2(18)$ & $1(9)$ & $0(0)$ & $0(0)$ & $0(0)$ & $0(0)$ \\
\hline South Asia & 7 & $2(29)$ & $1(14)$ & $3(43)$ & $1(14)$ & $0(0)$ & $0(0)$ & $0(0)$ \\
\hline Western Europe & 20 & $9(45)$ & $8(40)$ & $1(5)$ & $0(0)$ & $1(5)$ & $0(0)$ & $1(5)$ \\
\hline \multicolumn{9}{|l|}{ World Bank group } \\
\hline Low income & 21 & $4(19)$ & $2(10)$ & $5(24)$ & $10(48)$ & $0(0)$ & $0(0)$ & $0(0)$ \\
\hline Lower middle income & 35 & $8(23)$ & $7(20)$ & $13(37)$ & $3(9)$ & $1(3)$ & $3(9)$ & $0(0)$ \\
\hline Upper middle income & 41 & $22(54)$ & $5(12)$ & $11(27)$ & $1(2)$ & $0(0)$ & $1(2)$ & $1(2)$ \\
\hline High income & 56 & $28(50)$ & $18(32)$ & $6(11)$ & $1(2)$ & $1(2)$ & $1(2)$ & $1(2)$ \\
\hline
\end{tabular}

18). Many countries $(70 \%, 109 / 156)$ did not have enough nephrologists, interventional radiologists for haemodialysis access $(66 \%, 103 / 156)$, surgeons for peritoneal dialysis access $(51 \%, 79 / 156)$, or transplant surgeons (65\%, 102/156; eFig 18). Compared with the previous Global Kidney Health Atlas survey, the median number of nephrologists worldwide has increased by $0.22 \mathrm{pmp}$ (eAppendix 5).This improvement corresponds with income level, with low income countries reporting the lowest increase $(0.03 \mathrm{pmp})$, followed by lower middle (0.12 pmp), upper middle (0.53 pmp), and high (0.82 pmp) income countries (eAppendix 5).

\section{Global distribution of end stage kidney disease} registries and reporting on quality indicators of kidney replacement therapy

Respondents from 13 countries reported registries for acute kidney injury and those from 19 reported registries for non-dialysis chronic kidney disease (eTable 10). Most countries surveyed had registries for dialysis $(66 \%, 101 / 154)$ and kidney transplantation (57\%, 88/154; eTable 10).

Respondents were asked how often their countries measured and reported key quality indicators for kidney replacement therapy service delivery. Of 144 countries with haemodialysis services, 77 (53\%) measured patient reported outcome measures at least $50 \%$ of the time (eFig 19). Commonly reported indicators included blood pressure, haemoglobin/packed cell volume, small solute clearance, bone mineral markers, technique, and patient survival (eFig 19). Among the 112 countries with kidney transplantation services, 65 (58\%) measured patient reported outcome measures at least $50 \%$ of the time (eFig 20). A large proportion of countries reported patient survival $(77 \%, 86 / 111)$, kidney allograft function $(73 \%, 82 / 112)$, and graft survival (72\%, 80/111; eFig 20).

\section{Leadership and governance}

Oversight of end stage kidney disease varied across countries and regions. Care was managed by national governments in 89 (56\%) of 159 countries; hospitals, trusts, and organisations in 61 (38\%) countries; provincial, regional, or state governments in 34 (21\%) countries; non-governmental organisations in seven (4\%) countries; and other management structures in 12 (8\%) countries (eTable 11). Advocacy and support for end stage kidney disease and kidney replacement therapy varied across countries and regions (eTable 12).

Country variations in paediatric kidney care services Nearly a quarter $(37 / 157,24 \%)$ of countries reported that access to kidney replacement therapy differed between children and adults. Variation was highest among low income countries $(13 / 23,57 \%)$ followed by lower middle $(14 / 36,39 \%)$, upper middle $(5 / 41$, $12 \%)$, and high (5/57, 9\%) income countries. Organisation or delivery of care for end stage kidney disease also differed between children and adults in 47 (30\%) of 157 countries. Similarly, variation decreased as income level increased. Of 23 low income countries, $14(61 \%)$ reported differences between children and adults, followed by 14 (39\%) of 36 lower middle, eight (20\%) of 41 upper middle, and 11 (19\%) of 57 high income countries.

\section{Changes in region and country reports from 2017 to} 2019

This survey included 160 countries compared with 125 in the initial survey, ${ }^{16}$ and covered over 98\% (7338.5 


\begin{tabular}{|c|c|c|c|c|c|c|c|}
\hline \multirow[b]{3}{*}{ Category } & \multirow{3}{*}{$\begin{array}{l}\text { No of } \\
\text { responding } \\
\text { countries }\end{array}$} & \multicolumn{6}{|c|}{ All patients with kidney transplant } \\
\hline & & \multicolumn{2}{|c|}{ Public funding } & \multirow{2}{*}{$\begin{array}{l}\text { Mix of public } \\
\text { and private } \\
\text { funding }\end{array}$} & \multicolumn{2}{|c|}{ Private funding } & \multirow[b]{2}{*}{$\begin{array}{l}\text { Multiple } \\
\text { systems* }\end{array}$} \\
\hline & & $\begin{array}{l}\text { Free at point } \\
\text { of delivery }\end{array}$ & $\begin{array}{l}\text { Some fees at point } \\
\text { of delivery }\end{array}$ & & $\begin{array}{l}\text { Out of } \\
\text { pocket }\end{array}$ & $\begin{array}{l}\text { Heath } \\
\text { insurance }\end{array}$ & \\
\hline Overall & 113 & $64(57)$ & $20(18)$ & $15(13)$ & $6(5)$ & $5(4)$ & $3(3)$ \\
\hline \multicolumn{8}{|l|}{ ISN region } \\
\hline Africa & 14 & $5(36)$ & $1(7)$ & $4(29)$ & $3(21)$ & $1(7)$ & $0(0)$ \\
\hline $\begin{array}{l}\text { Eastern and central } \\
\text { Europe }\end{array}$ & 18 & $17(94)$ & $1(6)$ & $0(0)$ & $0(0)$ & $0(0)$ & $0(0)$ \\
\hline $\begin{array}{l}\text { Latin America and } \\
\text { Caribbean }\end{array}$ & 17 & $7(41)$ & $2(12)$ & $3(18)$ & $1(6)$ & $3(18)$ & $1(6)$ \\
\hline Middle East & 11 & $9(82)$ & $1(9)$ & $0(0)$ & $0(0)$ & $1(9)$ & $0(0)$ \\
\hline NIS and Russia & 7 & $5(71)$ & $0(0)$ & $0(0)$ & $1(14)$ & $0(0)$ & $1(14)$ \\
\hline North America & 5 & $3(60)$ & $1(20)$ & $1(20)$ & $0(0)$ & $0(0)$ & $0(0)$ \\
\hline North and east Asia & 7 & $2(29)$ & $5(71)$ & $0(0)$ & $0(0)$ & $0(0)$ & $0(0)$ \\
\hline OSEA & 10 & $5(50)$ & $2(20)$ & $3(30)$ & $0(0)$ & $0(0)$ & $0(0)$ \\
\hline South Asia & 6 & $1(17)$ & $1(17)$ & $3(50)$ & $1(17)$ & $0(0)$ & $0(0)$ \\
\hline Western Europe & 18 & $10(56)$ & $6(33)$ & $1(6)$ & $0(0)$ & $0(0)$ & $1(6)$ \\
\hline \multicolumn{8}{|l|}{ World Bank group } \\
\hline Low income & 5 & $1(20)$ & $1(20)$ & $1(20)$ & $2(40)$ & $0(0)$ & $0(0)$ \\
\hline Lower middle income & 24 & $10(42)$ & $2(8)$ & $5(21)$ & $4(17)$ & $3(13)$ & $0(0)$ \\
\hline Upper middle income & 34 & $23(68)$ & $3(9)$ & $4(12)$ & $0(0)$ & $2(6)$ & $2(6)$ \\
\hline High income & 50 & $30(60)$ & $14(28)$ & $5(10)$ & $0(0)$ & $0(0)$ & $1(2)$ \\
\hline
\end{tabular}

million/7501.3 million) of the world population (eAppendices 4 and 5). It examined the availability of kidney replacement therapy, its accessibility, quality, and affordability. Comparison of those countries responding to both iterations of the survey $(n=113)$ showed that some availability of chronic haemodialysis was reported in both surveys. Chronic peritoneal dialysis was available in $90(80 \%)$ of 113 countries in both surveys. Four countries (Bolivia, Egypt, Fiji, and Swaziland) without peritoneal dialysis availability previously reported this as available in the current survey, whereas four countries (Armenia, Kenya, Syria, and Uganda) with previously reported peritoneal dialysis available now reported non-availability (eAppendices 4 and 5). Kidney transplantation was available in $87(77 \%)$ of 113 countries in the previous survey compared with $88(78 \%)$ of 113 countries in this survey (eAppendices 4 and 5). Registries for chronic kidney disease and acute kidney injury existed in seven $(6 \%)$ and six $(5 \%)$ countries in the previous survey, compared with $11(10 \%)$ and seven (6\%) countries in this survey, respectively (eAppendices 4 and 5).

All the 47 additional countries in this survey reported at least some availability of chronic haemodialysis. Chronic peritoneal dialysis and kidney transplantation were available in $28(60 \%)$ and $23(49 \%)$ of these countries, respectively (eAppendices 4 and 5).

\section{Discussion}

The aim of the Global Kidney Health Atlas initiative is to document the state of kidney care across six domains of the health system worldwide, and to provide a score card to evaluate capacity for integrated delivery of kidney related healthcare, including dialysis, transplantation, and conservative care. ${ }^{21}$ The first assessment in 2017 showed variability in global kidney care. Considerable gaps in care were found across all domains, particularly in low income and lower middle income countries. ${ }^{16}$ This survey extends these findings by providing information on the full spectrum of care for end stage kidney disease. It provides information also on other services, such as registry and reporting of quality measures and the workforce necessary for optimal care.

This document describes the results of the 2019 survey, two years after the first. It aims to assess global capacity to deliver the structures and organisation for end stage kidney disease care in accordance with the key building blocks of a functional health system (availability, accessibility, quality, and affordability).

\section{Principal findings of the study}

Findings from this survey show that most participating countries $(64 \%, 102 / 159)$ provided public funding for kidney replacement therapy. Fewer than half $(48 \%$, $11 / 23$ ) of low income countries and just over half $(57 \%$, 21/37) of lower middle income countries provided public funding. This greatly reduces access to care in countries with fewer resources, resulting in potentially preventable death or morbidity. The concentration of nephrologists in high income countries was over 60 times that in low income countries. Most low income countries also reported shortages of interventional radiologists, surgeons, and transplant coordinators. Nearly all countries offered haemodialysis, and three quarters offered peritoneal dialysis and transplantation services. Few low income countries, however, provided these services. The costs of chronic haemodialysis facilities are high. More affordable peritoneal dialysis might enable poorer countries to improve their capacity to deliver care for end stage 
kidney disease. Alternatively, more affordable models of care, such as point of care dialysate production (eg, the Affordable Dialysis Project), ${ }^{29}$ simplification of technology equipment, and use of community based multi-user self care facilities, might help to provide more sustainable kidney replacement therapy in lower middle income countries. Services to manage complications of end stage kidney disease, such as anaemia, high blood pressure, electrolyte disorders, metabolic acidosis, and renal bone disease, were also limited, especially in low and lower middle income countries.

Kidney transplantation in suitable patients provides the best outcomes at the lowest cost. Development of sustainable programmes is often constrained by a lack of access to key ancillary services, such as tissue typing laboratories and surgical expertise. Partnership with regional professional associations, industry, and nearby countries willing to share resources could increase local capacity.

This survey provides new information on the availability of, and capacity for, conservative kidney management. The availability of conservative kidney management did not appear to be associated with income level, primarily because the provision of choice restricted conservative kidney management was included. The availability of chosen or medically advised conservative kidney management increased with country income level: 40 (71\%) of 56 high income countries offered conservative kidney management, compared with 21 (51\%) of 41 upper middle, 10 (29\%) of 35 lower middle, and six (27\%) of 22 low income countries. When kidney replacement therapy is available, the decision to choose conservative kidney management requires shared decision making between providers and patients. Factors such as lifestyle, values, health outcomes, and quality of life, should be considered. ${ }^{4}$ The expertise and infrastructure required to support this important choice will become increasingly important as kidney replacement therapy becomes more widely available.

\section{Health policy implications}

End stage kidney disease is well recognised as a major public health concern. Its treatment is expensive (consuming 2-3\% of the healthcare budget in wealthy nations), and a burden to patients, families, and the healthcare system. ${ }^{10}$ The problem is a growing one, with the incidence of end stage kidney disease rising worldwide, and the fastest growth occurring in low and middle income countries. ${ }^{5}$ Access to treatment is limited in these countries. For example, an estimated 2.3 to 7.1 million people who required kidney replacement, mainly in low and middle income countries, are thought to have died because they were unable to receive it. ${ }^{5}$ Access to care for end stage kidney disease care is thus critical to reducing global mortality from non-communicable diseases.

Our findings have important implications for patients and their families, healthcare professionals, and policy makers. As the magnitude of the burden of end stage kidney disease and financial consequences for the health system become increasingly apparent, the need to prioritise prevention becomes critical. This need is particularly true for low and middle income countries $^{2} 3031$ and vulnerable and disadvantaged populations in high income regions. ${ }^{30} 31$ Prevention of chronic kidney disease and end stage kidney disease is much more cost effective than providing care for end stage kidney disease. ${ }^{30} 32$ However, optimal prevention and treatment of kidney disease will not obviate the need for kidney replacement.

Our study identified inequities in kidney care delivery among children, particularly in low and lower middle income countries. The variability in access to care among marginalised population groups, particularly women and children, should also be dealt with.

Hence, if there were no financial constraints, end stage kidney disease care should ideally be available as a mix of peritoneal dialysis, haemodialysis, transplantation, and conservative kidney management (that is, non-dialytic care), and patients should be able to choose and move between the different modalities. For suitable patients, transplantation provides the optimal length and quality of life. ${ }^{33}$ For a substantial proportion of the rest, the best option is conservative kidney management because many patients will want kidney replacement therapy but do not have immediate access to it. Although conservative kidney management is an essential component of an integrated end stage kidney disease care programme, it should not be seen as a low cost alternative to the development of kidney replacement therapy programmes in low and middle income countries. ${ }^{34}$ If resource constraints limit the availability of kidney replacement therapy, then conservative kidney management should be clearly identified as choice restricted.

The implications of our findings in relation to the activities of other stakeholders (such as the WHO, World Bank, and others) already working to close gaps in care should also be highlighted. ${ }^{35} 36$ These include the WHO triple billion target aimed at improving access to primary healthcare while ensuring sustainable financing and financial protection, refining national health policies, and developing effective surveillance systems. ${ }^{37}$ Global efforts to achieve the sustainable development goals align with the implications of our findings. Achieving these goals will enable countries to achieve a degree of prosperity so that kidney replacement therapy could be provided without a net loss due to opportunity cost. ${ }^{3538}$

\section{Strengths and weaknesses of the study}

Our manuscript has several key strengths. The survey was based on a well validated conceptual framework for assessing care capacity for other chronic diseases and used the WHO health system building blocks. Data were reviewed for accuracy by regional and national stakeholders with local knowledge of their countries and regions. Furthermore, responses were collected from several countries covering almost the entire global population (98\%, 7338.5 million/7501.3 
million); coverage across regions and income levels was also good. To deal with some of the limitations of the first survey, we assessed other measurements of health system performance. These measurements include availability, accessibility, financing, quality and monitoring, and regional variability.

This survey, however, shares some limitations with its predecessor. Questionnaire surveys could introduce subjectivity (social desirability bias), and depend on respondents' knowledge, expertise, and perceptions. The survey questions were assessed for face validity, but our findings depend on how correctly respondents represented the status of services. Therefore, we worked closely with the ISN's regional boards to select respondents with a range of kidney care knowledge and expertise. At the same time, we ensured adequate regional representation, and corroborated findings with regional leaders and secondary data sources. The relative dearth in quantity and quality of information available from low and middle income countries should be acknowledged. The data from these countries could depend particularly on regional experts rather than national databases, which might have affected the interpretation and application of data from those regions.

We selected countries with available stakeholders to complete the surveys. Only 36 countries were not included in this survey, and they mostly lacked kidney care services or relied on neighbouring countries to provide them. Most of these excluded countries were independent territories and small islands. If they did not participate owing to limited information or resources or political focus on kidney care, their exclusion might have resulted in an overestimated capacity. These countries, however, comprised a range of geographical and economic levels. We speculate that their lack of participation was random, and probably did not affect the overall estimates. As we collected data from countries covering 98\% (7338.5 million/7501.3 million) of the global population, the proportion excluded from these 36 countries was minimal.

\section{Conclusions}

This work provides comprehensive data on the capacity of countries (including low income nations) to provide optimal care for patients with end stage kidney disease. The first iteration of the Global Kidney Health Atlas demonstrated significant interregional and intraregional variability in global kidney care, with appreciable gaps in the key health system building blocks (eg, care structures, workforce, financing). ${ }^{16} 17$ This study provides detail on accessibility, affordability, and quality of dialysis, transplantation, and conservative care, which were not covered by its predecessor. Global variations in the burden of kidney disease, related care practices, and their determinants have been well documented. This study documents consistent and comparable data using a formal framework to describe global capacity to deliver care to those with kidney failure. The data collection involved an international collaboration across major stakeholders from 160 countries containing 98\% (7338.5 million/7501.3 million) of the world population. The work provides a policy and advocacy tool for promoting access to kidney care across the globe. Our findings will help policy makers to make more informed decisions about resource allocation and prioritisation of services. Our findings also affect strategies to reduce the societal burden of chronic kidney disease and track national progress towards equitable and sustainable care throughout the continuum of kidney care. ${ }^{363940}$

\section{AUTHOR AFFILIATIONS}

${ }^{1}$ Division of Nephrology and Immunology, Department of Medicine, University of Alberta, Edmonton, AB T6B 2B7, Canada

${ }^{2}$ Division of Nephrology, Department of Medicine, University of British Columbia, Vancouver, BC, Canada

${ }^{3}$ Department of Community Health Sciences, University of Calgary, Calgary, AB, Canada

${ }^{4}$ University of Ottawa, Ottawa, ON, Canada

${ }^{5}$ Faculty of Medicine and Biomedical Sciences, Yaounde General Hospital, University of Yaounde I, Yaounde, Cameroon

${ }^{6}$ Division of Nephology and Hypertension, Department of Medicine, Saint Louis University, Saint Louis, MO, USA

${ }^{7}$ Urinary Tract Diseases Department, Faculty of Medicine and Pharmacy of Casablanca, University Hassan II of Casablanca, Casablanca, Morocco

${ }^{8}$ Nephrology Division, Department of Internal Medicine, The Specialty Hospital, Amman, Jordan

${ }^{9}$ Oxford Kidney Unit, Oxford University Hospitals NHS Foundation Trust, Oxford, UK

${ }^{10}$ Department of Renal Medicine, Singapore General Hospital, Singapore

${ }^{11}$ George Institute for Global Health, UNSW, New Delhi, India

${ }^{12}$ Nuffield Department of Clinical Medicine, University of Oxford, Oxford, UK

${ }^{13}$ Manipal Academy of Higher Education (MAHE), Manipal, Karnataka, India

${ }^{14}$ Division of Nephrology and Hypertension, University of California Irvine Medical Center, Orange, CA, USA

${ }^{15}$ UCLA Fielding School of Public Health in Irvine and Los Angeles, CA, USA

${ }^{16}$ Department of Nephrology, Monash Medical Centre, Monash Health, Clayton, VIC, Australia

${ }^{17}$ Department of Medicine, Monash University, Clayton, VIC, Australia ${ }^{18}$ Department of Medicine, University of Tennessee Health Science Center, Memphis, TN, USA

${ }^{19}$ Memphis VA Medical Center, Memphis, TN, USA

${ }^{20}$ Institute of Biomedical Ethics and the History of Medicine, University of Zurich, Zurich, Switzerland

${ }^{21}$ Renal Division, Brigham and Women's Hospital, Harvard Medical School, Boston, MA, USA

${ }^{22}$ George Institute for Global Health, Newtown, NSW, Australia

${ }^{23}$ Salford Royal NHS Foundation Trust, Salford, UK

${ }^{24}$ University of Manchester, Manchester, UK

${ }^{25}$ Division of Nephrology, Department of Medicine, Hasheminejad Kidney Center, Iran University of Medical Sciences, Tehran, Iran

${ }^{26}$ Division of Nephrology, St Michael's Hospital and the Keenan Research Centre in the Li Ka Shing Knowledge Institute, St Michael's Hospital, Toronto, ON, Canada

${ }^{27}$ Division of Nephrology, Department of Medicine, University of Toronto, Toronto, ON, Canada

${ }^{28}$ Department of Nephrology, Kidney Foundation Hospital and Research Institute, Dhaka, Bangladesh

${ }^{29}$ Intensive Care Nephrology and Transplantation Department, Hopital Tenon, Assistance Publique-Hopitaux de Paris, Paris, France

${ }^{30}$ Sorbonne Université, Paris, France 
${ }^{31}$ Department of Intensive Care, Austin Health, Melbourne, VIC, Australia

${ }^{32}$ School of Medicine, University of Melbourne, Melbourne, VIC, Australia

${ }^{33}$ Dialysis Unit, CASMU-IAMPP, Montevideo, Uruguay

${ }^{34}$ Nephrology Development Clinical Center, Tbilisi State Medical University, Tbilisi, Georgia

${ }^{35}$ Department of Nephrology, General University Hospital, Charles University, Prague, Czech Republic

${ }^{36}$ Department of Medicine, Faculty of Medicine, King Chulalongkorn Memorial Hospital, Chulalongkorn University, Bangkok, Thailand

${ }^{37}$ Bhumirajanagarindra Kidney Institute, Bangkok, Thailand

${ }^{38}$ Division of Nephrology, Bezmialem Vakif University, Istanbul, Turkey

${ }^{39}$ Department of Medicine, University of Hong Kong, Queen Mary Hospital, Hong Kong

${ }^{40}$ Kidney Research Center, Department of Nephrology, Chang Gung Memorial Hospital, Linkou, Taiwan

${ }^{41}$ College of Medicine, Chang Gung University, Taoyuan, Taiwan

${ }^{42}$ Department of Internal Disease and Nephrology, North-Western

State Medical University named after I I Mechnikov, Saint Petersburg, Russia

${ }^{43}$ Department of Nephrology and Dialysis, Pavlov First Saint Petersburg State Medical University, Saint Petersburg, Russia

${ }^{44}$ Renal Division, Department of Medicine, Peking University First Hospital, Beijing, China

${ }^{45}$ Key Lab of Renal Disease, Ministry of Health of China, Beijing, China

${ }^{46}$ Key Lab of Chronic Kidney Disease Prevention and Treatment, Ministry of Education of China; Beijing, China

${ }^{47}$ Peking-Tsinghua Center for Life Sciences, Beijing, China

${ }^{48}$ ERA-EDTA Registry, Department of Medical Informatics, Academic Medical Center, Amsterdam Public Health Research Institute, University of Amsterdam, Amsterdam, Netherlands

${ }^{49}$ Population Health Sciences, University of Bristol, Bristol, UK

${ }^{50}$ Richard Bright Renal Unit, Southmead Hospital, North Bristol NHS Trust, Bristol, UK

${ }^{51}$ George Institute for Global Health, University of New South Wales Sydney, Sydney, NSW, Australia

${ }^{52}$ Division of Nephrology and Hypertension, University of Cape Town, Cape Town, South Africa

${ }^{53}$ Kidney and Hypertension Research Unit, University of Cape Town, Cape Town, South Africa

${ }^{54}$ Department of Medicine, University of Calgary, Calgary, AB, Canada

${ }^{55}$ Pan-American Health Organization/World Health Organization's Collaborating Centre in Prevention and Control of Chronic Kidney Disease, University of Calgary, Calgary, AB, Canada

${ }^{56}$ University of Leicester, Leicester, UK

${ }^{57}$ Centre for Transplantation and Renal Research, Westmead Institute for Medical Research, University of Sydney, Sydney, NSW, Australia

${ }^{58}$ Centre for Kidney Disease Research, University of Queensland, Brisbane, QLD, Australia

${ }^{59}$ Translational Research Institute, Brisbane, QLD, Australia

${ }^{60}$ Metro South and Ipswich Nephrology and Transplant Services, Princess Alexandra Hospital, Brisbane, QLD, Australia

We thank Sandrine Damster, senior research project manager at the International Society of Nephrology, and Alberta Kidney Disease Network staff (G Houston, S Szigety, and S Tiv) for helping to organise and conduct the survey and providing project management support: Jo-Ann Donner, Coordinator at the International Society of Nephrology, for her prominent role in the manuscript management and submission process; the International Society of Nephrology staff (Charu Malik, Claire Van Der Linden, Luisa Strani, and Luca Segantini) for their support; and the Global Kidney Health Atlas steering committee, International Society of Nephrology's executive committee and regional leadership, and Affiliate Societies' leaders at the regional and country levels for their help, particularly with identification of survey respondents and data acquisition, which ensured the success of this initiative. None of the persons acknowledged received compensation for their role in the study.
Contributors: AKB and DWJ had full access to all of the data in the study and take responsibility for the integrity of the data and the accuracy of the data analysis. AKB, MT, AL, DCH, and DWJ contributed to the study concept and design. All the authors contributed to the acquisition, analysis, and interpretation of data and to the critical revision of the manuscript for important intellectual content. AKB, $\mathrm{MAO}, \mathrm{ML}$, and DWJ drafted the manuscript. FY, NW, ML, and MAO conducted the statistical analysis. AKB, AL, and DWJ obtained funding. MAO, SS, ML, NW, and FY provided administrative, technical, and material support. Co-chairs AKB and DWJ of the International Society of Nephrology's Global Kidney Health Atlas supervised the study. The corresponding author attests that all listed authors meet authorship criteria and that no others meeting the criteria have been omitted. AKB is the guarantor.

Funding: This work was supported by the International Society of Nephrology (grant RES0033080 to the University of Alberta). The International Society of Nephrology provided administrative support for the design and implementation of the study and data collection activities. The authors were responsible for data management, analysis, and interpretation, as well as manuscript preparation, review, and approval, and the decision to submit the manuscript for publication. The International Society of Nephrology has no role in the analysis, interpretation of data, writing of the manuscript, decision to submit the article for publication.

Competing interests: All authors have completed the ICMJE uniform disclosure form at www.icmje.org/coi_disclosure.pdf, and declare: the submitted work was supported by the International Society of Nephrology as part of its global initiatives of improving kidney health as a not-for-profit professional organisation; the authors (although all members of the International Society of Nephrology) carried out the work on a voluntary basis; outside the submitted work, PH reports grants from Chiesi Pharmaceuticals; VI reports grants from Baxter Healthcare and GlaxoSmithKline, and consultancy fees from NephroPlus, Biocon, and George Clinical; KK-Z reports personal fees from Abbott, Abbvie, Alexion, Amag Pharma, Amgen, AstraZeneca, Aveo, Baxter, Chugai, Dr Shaer, Fresenius Medical Care, Genentech, Haymarket, Hospira, Kabi, Keryx, Novartis, PCORI, Pfizer, Relypsa, Resverlogix, Sandoz, Sanofi, Vifor, ZS-Pharma, and UpToDate, free access to national data and biobank specimens from DaVita, and grants and personal fees from Shire and the National Institutes of Health; PGK reports conference attendance support from Amgen Australia and honorarium from Bayer Australia; CPK reports personal fees from Abbott, Abbvie, Amgen, AstraZeneca, Bayer, Dr Schar, Fresenius Medical Care, GlaxoSmithKline, Keryx, Sanofi-Aventis, and Takeda, and grants from Shire; BN reports travel expenses from Janssen; JP reports grants and personal fees from Baxter Healthcare, Fresenius Medical Care, and Davita Healthcare partner; RTK reports personal fees from Baxter; AY-MW reports grants from Sanofi and Otsuka; KJJ reports personal fees from Fresenius Medical Care; VP reports personal fees for advisory boards or scientific presentations from Janssen, Merck, Retrophin, and Servier, fees paid to his institution for advisory boards, steering committee roles, or scientific presentations from Abbvie, Astellas, AstraZeneca, Baxter Boehringer Ingelheim, Dimerix, Durect, Gilead, Janssen, Novartis, Novo Nordisk, Pfizer, Pharmalink, Relypsa, Sanofi, and Tricida, and grants from the National Health and Medical Research Council of Australia, Janssen, and Pfizer and senior research fellowship from National Health and Medical Research Council of Australia; MT reports grants from the Canadian Institutes for Health Research during conduct of the study; DWJ reports grants and personal fees from Baxter Healthcare and Fresenius Medical Care, travel sponsorship from Amgen, personal fees from AstraZeneca, and grants from the National Health and Medical Research Council of Australia, during the conduct of the study; the remaining authors have nothing to declare.

Ethical approval: The project was approved by the University of Alberta's research ethics committee (protocol number PRO00063121) and all participants provided informed consent. Individual patient data were not used in this study; it was a survey of healthcare structure and delivery and was not based on patient data. Data sharing: No additional data available.

The lead author affirms that the manuscript is an honest, accurate, and transparent account of the study being reported; that no important aspects of the study have been omitted; and that any discrepancies from the study as planned have been explained.

Publisher's note: Published maps are provided without any warranty of any kind, either express or implied. BMJ remains neutral with regard to jurisdictional claims in published maps. 
This is an Open Access article distributed in accordance with the Creative Commons Attribution Non Commercial (CC BY-NC 4.0) license, which permits others to distribute, remix, adapt, build upon this work non-commercially, and license their derivative works on different terms, provided the original work is properly cited and the use is noncommercial. See: http://creativecommons.org/licenses/by-nc/4.0/.

1 Levey AS, Coresh J. Chronic kidney disease. Lancet 2012;379:16580. doi:10.1016/S0140-6736(11)60178-5

2 Levin A, Tonelli M, Bonventre J, et al, ISN Global Kidney Health Summit participants. Global kidney health 2017 and beyond: a roadmap for closing gaps in care, research, and policy. Lancet 2017;390:1888-917. doi:10.1016/S01406736(17)30788-2

3 Coresh J, Jafar TH. Disparities in worldwide treatment of kidney failure. Lancet 2015;385:1926-8. doi:10.1016/S0140-6736(14)61890-0

4 Davison SN, Levin A, Moss AH, et al, Kidney Disease: Improving Global Outcomes. Executive summary of the KDIGO Controversies Conference on Supportive Care in Chronic Kidney Disease: developing a roadmap to improving quality care. Kidney Int 2015;88:447-59. doi:10.1038/ki.2015.110

5 Liyanage T, Ninomiya $T$, Jha $V$, et al. Worldwide access to treatment for end-stage kidney disease: a systematic review. Lancet 2015;385:1975-82. doi:10.1016/S01406736(14)61601-9

6 Winkelmayer WC, Weinstein MC, Mittleman MA, Glynn RJ, Pliskin JS. Health economic evaluations: the special case of end-stage renal disease treatment. Med Decis Making 2002;22:417-30. doi:10.1177/027298902320556118

7 Xie Y, Bowe B, Mokdad AH, et al. Analysis of the Global Burden of Disease study highlights the global, regional, and national trends of chronic kidney disease epidemiology from 1990 to 2016. Kidney Int 2018;94:567-81. doi:10.1016/j.kint.2018.04.011

8 Crews DC, Bello AK, Saadi G, World Kidney Day Steering Committee. Burden, access, and disparities in kidney disease. Kidney Int 2019;95:242-8. doi:10.1016/j.kint.2018.11.007

9 Fuller DS, Bieber BA, Pisoni RL, et al. International comparisons to assess effects of payment and regulatory changes in the United States on anemia practice in patients on hemodialysis: the dialysis outcomes and practice patterns study. J Am Soc Nephrol 2016;27:2205-15. doi:10.1681/ASN.2015060673

10 Harris DCH, Davies SJ, Finkelstein FO, et al, Working Groups of the International Society of Nephrology's 2nd Global Kidney Health Summit. Increasing access to integrated ESKD care as part of universal health coverage. Kidney Int 2019;95(4S):S1-33. doi:10.1016/j.kint.2018.12.005

11 Moreno Velásquez I, Tribaldos Causadias M, Valdés R, et al. Endstage renal disease-financial costs and years of life lost in Panama: a cost-analysis study. BMJ Open 2019;9:e027229. doi:10.1136/ bmjopen-2018-027229

12 Pisoni RL, Zepel L, Fluck R, et al. International differences in the location and use of arteriovenous accesses created for hemodialysis: results from the Dialysis Outcomes and Practice Patterns Study (DOPPS). Am J Kidney Dis 2018;71:469-78. doi:10.1053/j. ajkd.2017.09.012

13 Shah KK, Murtagh FEM, McGeechan K, et al. Health-related quality of life and well-being in people over 75 years of age with end stage kidney disease managed with dialysis or comprehensive conservative care: a cross-sectional study in the UK and Australia. BMJ Open 2019;9:e027776. doi:10.1136/bmjopen-2018-027776

14 Thomas B, Matsushita K, Abate KH, et al, Global Burden of Disease 2013 GFR Collaborators, CKD Prognosis Consortium, Global Burden of Disease Genitourinary Expert Group. Global cardiovascular and renal outcomes of reduced GFR. J Am Soc Nephrol 2017;28:2167 79 doi:10.1681/ASN.2016050562

15 Thomas B, Wulf S, Bikbov B, et al. Maintenance dialysis throughout the world in years 1990 and 2010. J Am Soc Nephrol 2015;26:2621-33. doi:10.1681/ASN.2014101017

16 Bello AK, Levin A, Tonelli M, et al. Assessment of global kidney health care status. JAMA 2017;317:1864-81. doi:10.1001/ jama.2017.4046

17 Mandayam S, Winkelmayer WC. Worldwide preparedness for kidney health care. JAMA 2017;317:1838-9. doi:10.1001/jama.2017.2825

18 Bello AK, Johnson DW, Feehally J, et al. Global Kidney Health Atlas (GKHA): design and methods. Kidney Int Suppl (2011) 2017;7:14553. doi:10.1016/j.kisu.2017.08.001

19 Liu FX, Rutherford P, Smoyer-Tomic K, Prichard S, Laplante S. A global overview of renal registries: a systematic review. BMC Nephrol 2015;16:31. doi:10.1186/s12882-015-0028-2
20 World Health Organization. Global observatory on donation and transplantation. 2012. http://www.transplant-observatory.org/

21 World Health Organization. Monitoring the building blocks of health systems: a handbook of indicators and their measurement strategies. WHO Press, 2010.

22 Moran AE, Roth GA, Narula J, Mensah GA. 1990-2010 global cardiovascular disease atlas. Glob Heart 2014;9:3-16. doi:10.1016/j.gheart.2014.03.1220

23 Leowski J, Krishnan A. Capacity to control noncommunicable diseases in the countries of South-East Asia. Health Policy 2009;92:43-8. doi:10.1016/j.healthpol.2009.02.003

24 Stevens GA, Alkema L, Black RE, et al, The GATHER Working Group). Guidelines for Accurate and Transparent Health Estimates Reporting: the GATHER statement. Lancet 2016;388:e19-23. doi:10.1016/ S0140-6736(16)30388-9

25 Annual USRDS. Data report. United States Renal Data System. 2018 https://www.usrds.org/adr.aspx

26 World Health Organization. Assessing national capacity for the prevention and control of noncommunicable diseases - report of the 2015 global survey. WHO Press, 2015.

27 Weldring T, Smith SM. Patient-reported outcomes (PROs) and patient-reported outcome measures (PROMs). Health Serv Insights 2013:6:61-8. doi:10.4137/HSI.S11093

28 Eysenbach G. Improving the quality of web surveys: the Checklist for Reporting Results of Internet E-Surveys (CHERRIES). I Med Internet Res 2004;6:e34. doi:10.2196/jmir.6.3.e34

29 The George Institute. The Affordable Dialysis Project. https://www. georgeinstitute.org/projects/the-affordable-dialysis-project

30 Gansevoort RT, Correa-Rotter R, Hemmelgarn BR, et al. Chronic kidney disease and cardiovascular risk: epidemiology, mechanisms, and prevention. Lancet 2013;382:339-52. doi:10.1016/S01406736(13)60595-4

31 Purnell TS, Luo X, Cooper LA, et al. Association of race and ethnicity with live donor kidney transplantation in the United States from 1995 to 2014. JAMA 2018;319:49-61. doi:10.1001/jama.2017.19152

32 Jha V, Martin DE, Bargman JM, et al, International Society of Nephrology Ethical Dialysis Task Force. Ethical issues in dialysis therapy. Lancet 2017;389:1851-6. doi:10.1016/S01406736(16)32408-4

33 Jay CL, Cigarroa FG. Disparities in live donor kidney transplantation: related to poverty, race, or ethnicity?JAMA 2018;319:24-6. doi:10.1001/jama.2017.19617

34 Harrison TG, Tam-Tham H, Hemmelgarn BR, James MT, Sinnarajah A, Thomas CM. Identification and prioritization of quality indicators for conservative kidney management. Am J Kidney Dis 2019;73:174-83. doi:10.1053/i.ajkd.2018.08.014

35 Gostin LO, Friedman EA. The sustainable development goals: onehealth in the world's development agenda. JAMA 2015;314:2621-2 doi:10.1001/jama.2015.16281

36 Gostin LO. A framework convention on global health: health for all, justice for all. JAMA 2012;307:2087-92. doi:10.1001/ jama.2012.4395

37 WHO. 13th General Programme of Work (GPW 13) impact framework: targets and indicators. World Health Organization. 2018. https:// www.who.int/about/what-we-do/GPW13_WIF_Targets_and_ Indicators English.pdf

38 Klarenbach SW, Tonelli M, Chui B, Manns BJ. Economic evaluation of dialysis therapies. Nat Rev Nephrol 2014;10:644-52. doi:10.1038/ nrneph.2014.145

39 Bhutta ZA, Reddy KS. Achieving equity in global health: so near and yet so far. JAMA 2012;307:2035-6. doi:10.1001/jama.2012.4659

40 Gupta V, Katz R, Swaminathan S. Reimagining development assistance for health. N Engl I Med 2018;379:1891-3. doi:10.1056/ NEJMp1809808

Web appendix: Supplementary Online Content (listed) Web appendix 1: Global Kidney Health Atlas (GKHA) Questionnaire

Web appendix 2: Checklist for Reporting Results of Internet E-Surveys (CHERRIES)*

Web appendix 3: Dissemination Plans

Web appendix 4: Country-level comparison scorecards

Web appendix 5: Regional comparison scorecards

Web tables: eTables

Web figures: eFigures 